\section{Clivia miniata Red Peony: A New Double-flowered Clivia Cultivar}

\author{
Chong Wang and Yang Song \\ Department of Landscape Architecture, Liaoning Vocational College of \\ Ecological Engineering, Fengyang Road 186, Shenyang 110101, Liaoning, \\ China
}

Mingqian Wang, Jiajun Lei, and Li Xue
College of Horticulture, Shenyang Agricultural University, Dongling
Road 120, Shenyang 110866, Liaoning, China

Shizhong He

Shenyang Heshi Clivia Base, Dongling Road 120, Shenyang 110866, Liaoning, China

Additional index words. ornamental, breeding, multipetaled, flower color, tepal
The genus Clivia Lindl. belongs to the family Amaryllidaceae, which includes six diploid species $(2 n=2 x=22)$ and is naturally distributed in Southern Africa (Duncan, 2008). Clivia has been widely cultivated as one of the famous ornamental pot plants, with tremendous economic value worldwide for nearly a century (Rourke, 2002). The leaf and flower of clivia have always been regarded as two of the most important ornamental characteristics. In the past several decades, many clivia cultivars have been released, such as Clivia miniata Longwood Debutante, Longwood Fireworks, and Longwood Sunrise in the United States (Petravich, 2015); and Utopia Secret Desire, Utopia Secret Hope, Utopia Secret Love, and Utopia Secret Rose in South Africa (Kruger, 2018).

It was recorded that clivia was first introduced into Changchun City by a Japanese florist in 1932 (Zheng et al., 2012). Before 1990, it was appreciated only by the wealthy as a rare precious flower, but now it is very popular in China. It is cultivated mainly in Jilin and Liaoning Provinces, Northeast China. China is regarded as one of the largest clivia-producing countries in the world (Duncan, 2008), but only a few clivia cultivars have been released in China (Bao et al., 2014).

Usually, the flower of clivia is orange or yellow with six petals, including three inner petals and three outer petals. Although many clivia cultivars with special flower colors and shapes have been bred, such as green-petaled cultivar Angel's Smile, the pink-petaled cultivar Pink Champagne, and carnation-flowered shape cultivar Picotee, the double-flowered type is still rarely seen. We announce a new double-

Received for publication 10 Feb. 2021. Accepted for publication 14 Apr. 2021.

Published online 8 June 2021.

This research was funded by the Science and Technology Program of Liaoning Province (20180551290).

L.X. is the corresponding author. E-mail: lixue@ syau.edu.cn.

This is an open access article distributed under the CC BY-NC-ND license (https://creativecommons. org/licenses/by-nc-nd/4.0/). flowered clivia cultivar Clivia miniata Red Peony with an average of 13 petals per flower.

\section{Origin}

The new clivia cultivar Red Peony was derived from the cross of Clivia miniata 'WR' and ' $Z C$ ' at Heshi Clivia Base, Shenyang City, Liaoning Province, China. The female parent 'WR' and the male parent ' $Z C$ ' were collected from Changchun City, Jilin Province, China. The flower of 'WR' is red [orange-red group, Royal Horticultural Society (RHS) 33A (Royal Horticultural Society, 2007)] with a yellow throat (yellow group, RHS 6B) and an average of 7.8 petal per flower. The flower of ' $\mathrm{ZC}$ ' is light orange (orange-red group, RHS 34D) with a deep-green throat (green group, RHS 140C) and an average of 9.6 petal per flower. The stamen petaloid is observed in both parents, in which some stamens naturally mutate into petals.

In Mar. 2000, 24 flowers were pollinated in the cross of 'WR' and ' $\mathrm{ZC}$ ', and 154 hybrid seeds were obtained from 20 hybrid fruit. The hybrid seeds were sowed on a substrate filled with vermiculite:perlite (1:1) in the middle of May 2002. The seedlings were planted in leaf mold at a distance of $10 \times 40 \mathrm{~mm}$ in several seedlings were planted individually in pots when their fourth leaf emerged. In 2008, 117 surviving seedlings flowered, and the best, most-promising double-flowered individual, 'WZ 18', was evaluated in the greenhouse. It

The morphological characteristics observed include leaf length and width, flower color and size, flower number per inflorescence, petal number per flower, petal shape and size, stamen number per flower, and bloom duration. The color descriptions are based on the RHS Color Chart (Royal Horticultural Society, 2007) and are designated using RHS numbers. All data have been analyzed for significance using one-way analysis of variance (IBM SPSS version 19.0; Armonk, NY). Mean data were compared using Duncan's multiple range tests to determine significant differences $(P<0.05)$.

\section{Description}

The plant of Clivia miniata 'Red Peony' is of a medium size, at $45 \mathrm{~cm}$ tall. Leaves are $30.3 \mathrm{~cm}$ long by $8.7 \mathrm{~cm}$ wide, which is shorter than its parents, and the leaves grow obliquely upward (Table 1). The double flowers open with large overlapping tepals held in large umbels on sturdy scapes (Fig. 1) that rise nicely above the dark-green foliage. The scapes are $33 \mathrm{~cm}$ long; the umbels are $20 \mathrm{~cm}$ wide with an average of 18 florets, not reflexed; the flowers are $8.1 \mathrm{~cm}$ in diameter; and the tepals are multilayered, obovate, have a cuneate tip, and are $4.3 \mathrm{~cm}$ long by $3.2 \mathrm{~cm}$ wide. The petal number per flower is 13 on average, and can range up to 22 . There are 5 to 12 stamens per flower (average, 9.5). The flower is orange-red (RHS 32B) with a light-green throat (RHS 150B), and is larger than the male parent ' $\mathrm{ZC}$ '. 'Red Peony' has a longer inflorescence life than its parents 'WR' and 'ZC', and its bloom last for large pots when their second leaf emerged. The was named C. miniata 'Red Peony' in 2017.

Table 1. Morphological characteristics of 'Red Peony' and its parents 'WR' and 'ZC'.

\begin{tabular}{|c|c|c|c|}
\hline Characteristics & WR & $\mathrm{ZC}$ & Red Peony \\
\hline Leaf length $(\mathrm{mm})$ & $350.6 \pm 1.14 \mathrm{a}$ & $342.7 \pm 1.21 \mathrm{a}$ & $303.5 \pm 2.08 \mathrm{~b}$ \\
\hline Leaf width $(\mathrm{mm})$ & $85.5 \pm 0.12 \mathrm{a}$ & $86.9 \pm 0.22 \mathrm{a}$ & $86.8 \pm 1.23 \mathrm{a}$ \\
\hline Leaf color & $\begin{array}{l}\text { Green with } \\
\quad \text { yellow stripes }\end{array}$ & Green & $\begin{array}{l}\text { Green with unobvious } \\
\text { stripes }\end{array}$ \\
\hline Flower color & $\begin{array}{l}\text { Red }(33 \mathrm{~A}) \text { with } \\
\text { yellow } \\
\text { throat }(6 \mathrm{~B})\end{array}$ & $\begin{array}{l}\text { Light orange (34D) } \\
\text { with green } \\
\text { throat }(140 \mathrm{C})\end{array}$ & $\begin{array}{l}\text { Orange-red }(32 \mathrm{~B}) \text { with } \\
\text { yellow-green } \\
\text { throat }(150 \mathrm{~B})\end{array}$ \\
\hline $\begin{array}{l}\text { Flower diameter } \\
\quad(\mathrm{mm})\end{array}$ & $78.7 \pm 0.51 \mathrm{a}$ & $72.2 \pm 0.21 \mathrm{~b}$ & $81.0 \pm 0.38 \mathrm{a}$ \\
\hline $\begin{array}{l}\text { No. of flowers per } \\
\text { inflorescence }\end{array}$ & $26.2 \pm 0.61 \mathrm{a}$ & $22.7 \pm 0.42 b$ & $18.4 \pm 0.51 \mathrm{c}$ \\
\hline $\begin{array}{l}\text { No. of petals per } \\
\text { flower }\end{array}$ & $7.8 \pm 0.18 b$ & $9.6 \pm 0.39 \mathrm{~b}$ & $13.2 \pm 2.86 \mathrm{a}$ \\
\hline $\begin{array}{l}\text { No. of stamens per } \\
\text { flower }\end{array}$ & $7.2 \pm 0.43 \mathrm{~b}$ & $7.8 \pm 0.14 \mathrm{~b}$ & $9.5 \pm 0.25 \mathrm{a}$ \\
\hline Petal length (mm) & $48.1 \pm 0.21 \mathrm{a}$ & $44.6 \pm 0.21 \mathrm{~b}$ & $43.2 \pm 0.43 b$ \\
\hline Petal width (mm) & $22.7 \pm 0.32 b$ & $25.2 \pm 0.62 b$ & $32.1 \pm 0.59 \mathrm{a}$ \\
\hline Bloom duration (d) & $30.3 \pm 0.56 b$ & $31.8 \pm 0.48 \mathrm{~b}$ & $40.1 \pm 0.37 \mathrm{a}$ \\
\hline
\end{tabular}

Values denoted with different letters within each column show significant differences at $P<0.05$ with Duncan's multiple range tests. 


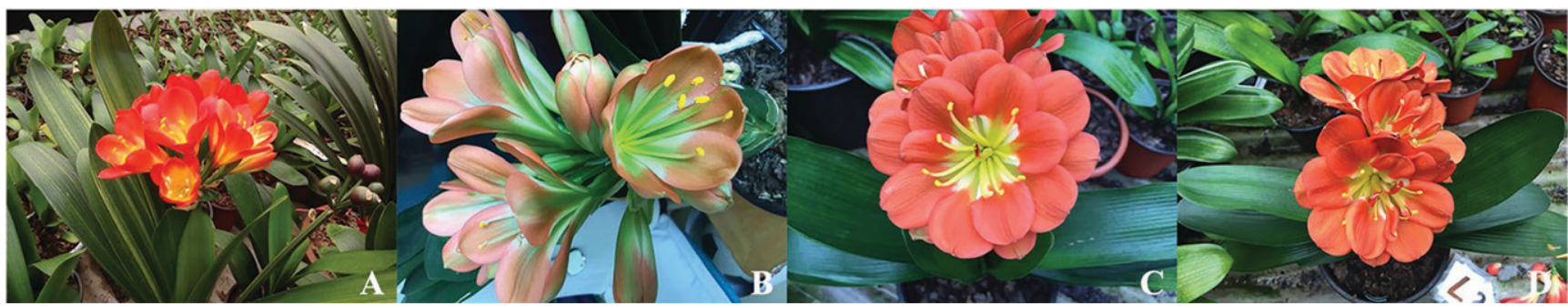

Fig. 1. The flowers of (A) the female parent 'WR', (B) the male parent 'ZC', and (C, D) 'Red Peony'.

$40 \mathrm{~d}$ in the greenhouse. Its parents have a bloom life of about $30 \mathrm{~d}$ at 18 to $23^{\circ} \mathrm{C}$. In conclusion, C. miniata 'Red Peony' is a promising, double-flowered cultivar with attractive flowers and a longer bloom duration than its singleflowered parents. It can also be used for further clivia breeding as a double-flowered parent.

\section{Availability}

'Red Peony' is available for research, and requests for samples of its seeds may be addressed to Dr. Wang (E-mail: 263038000@ qq.com) from the Department of Landscape Architecture, Liaoning Vocational College of Ecological Engineering, Liaoning, China.

\section{Literature Cited}

Bao, J.Z., F.T. Li, C.X. Liu, Y. Sun, H. Ma, T. Zhang, and X.L. Chen. 2014. A new Clivia miniata cultivar 'Yangjun 2'. Acta Hort. Sinica 41(8):1753-1754. (in Chinese).

Duncan, G. 2008. Grow clivias. 2nd ed. SANBI, Cape Town, South Africa.

Kruger, C. 2018. Clivia register. North American Clivia Society. 4 May 2021. <http://www. northamericancliviasociety.org/links.php\# interesting $5>$.

Petravich, A. 2015. Clivia breeding at Longwood Gardens. Proc. Ann. Mtg. Intl. Plant Propagators Soc. 1085:207-209.

Rourke, J.P. 2002. Clivia mirabilis (Amaryllidaceae: Haemantheae) a new species from Northern Cape, South Africa. Bothalia 32:1-7.

Royal Horticultural Society. 2007. RHS colour chart. 5th ed. Royal Horticultural Society, London, UK.

Zheng, Y.H., C. Jia, Y.H. Gu, F. Peng, W.R. Ma, and X.X. Chen. 2012. Advance on clivia research. Northern Hort. 19:189-195. (in Chinese). 